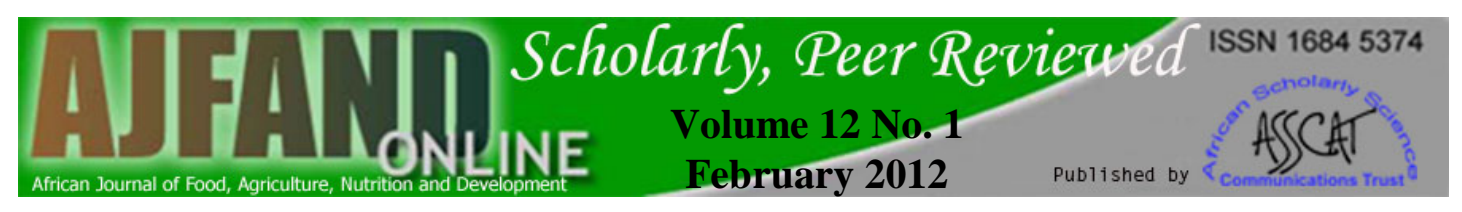

\title{
MICROENTERPRISE DEVELOPMENT COUPLED WITH NUTRITION EDUCATION CAN HELP INCREASE CAREGIVERS' INCOMES AND HOUSEHOLD ACCESSIBILITY TO ANIMAL SOURCE FOODS
}

$$
\text { Homiah PA }{ }^{1} \text {, Sakyi-Dawson } \mathrm{O}^{*^{2}} \text {, Bonsu } \mathrm{AM}^{1} \text { and GS Marquis }{ }^{3,4}
$$

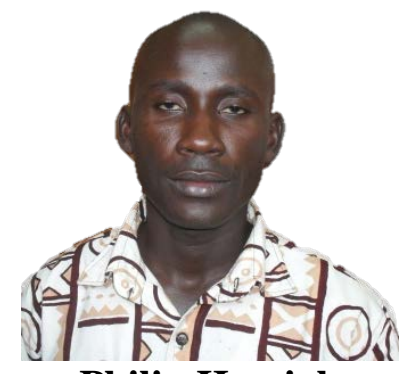

\author{
Philip Homiah
}

*Corresponding author email: osakyid@ug.edu.gh

${ }^{1}$ Department of Agricultural Economics and Agribusiness, College of Agriculture and Consumer Sciences University of Ghana, Legon, Ghana.

${ }^{2}$ Department of Agricultural Extension, College of Agriculture and Consumer Sciences, University of Ghana, Legon, Ghana.

${ }^{3}$ School of Dietetics and Human Nutrition, McGill University, Montreal, Canada.

${ }^{4}$ Department of Food Science and Human Nutrition, Iowa State University, Ames, USA. 


\section{ABSTRACT}

Low income and lack of knowledge about child nutrition have been identified as key constraints to the use of Animal Source Foods (ASF) in the diets of young Ghanaian children. To improve ASF consumption among children in Ghana, the Enhancing Child Nutrition through Animal Source Food Management (ENAM) project introduced an intervention that combined women's microenterprise development activities with nutrition education on the importance of ASF in children's diets. The present study assessed the effects of the intervention on the participants' enterprise performance, their contribution to key household and child-related expenditures as well as their households' purchases of ASF. Additionally, household ASF consumption was assessed in monetary terms (measured in Ghana cedis (GH4):1GHథ $=$ US\$ 0.92).A structured questionnaire was used to interview 80 caregivers who participated in the ENAM project activities in four intervention communities and 80 non-participant caregivers in four control communities. Information solicited included household characteristics, profits from microenterprises and contributions to household food and non-food expenditures. Significantly more participant caregivers expanded $(\mathrm{P}=0.004)$ and diversified $(\mathrm{P}=0.004)$ their enterprises and, as a result, tended to have higher average enterprise profits (GH\$19.3 \pm 2.2 vs. GH\$12.2 \pm 1.9 ; $\mathrm{P}=0.08)$ and significantly higher savings (GH\$62.9 \pm 2.2 vs. GH\$26.3 $\pm 1.9 ; \mathrm{P}<0.05)$ than non-participant caregivers. In addition, the intervention was associated with significantly higher percentage of monetary contributions by caregivers towards children's health expenses $(\mathrm{P}<0.05)$, school expenses $(\mathrm{P}<0.01)$ as well as expenses on clothing and footwear $(\mathrm{P}<0.01)$. Caregivers' mean percentage contribution to household food expenses also tended to be higher $(\mathrm{P}<0.1)$ for participants $(50.8 \pm$ $3.5 \%)$ then for non-participants $(41.8 \pm 4.1 \%)$. Participant households also tended to spend more money $(\mathrm{P}<0.10)$ and consumed significantly more amounts (in monetary value) of ASF $(\mathrm{P}<0.01)$ than non-participant households. Being a participant in the ENAM project's microenterprise development and nutrition education activities was associated with higher enterprise profits, savings deposits, contributions to householdand children-related expenditures, and ASF consumption at the household level.

Key words: Microcredit, Entrepreneurship, Income, Expenditures, Ghana 


\section{INTRODUCTION}

There is ample evidence that Animal Source Foods (ASF) have a beneficial role in children's physical and cognitive development due to their high quality protein and highly bioavailable micronutrients [1]. However, diets of children typically contain low levels of ASF. A participatory rapid appraisal identified low income and lack of caregivers' knowledge about the use of ASF as two key constraints to the use of ASF in the diets of young children in Ghana [2]. In most households studied, women were responsible for contributing the stew ingredients that included ASF, while men provided the cereal and tubers for the family pot. Since women primarily purchased ASF, the study concluded that interventions that increase women's income may be successful in improving children's diets.

In Ghana, women make up about $50 \%$ of the labour force and most of them are involved in microenterprises and retail trade and constitute the majority of owners in the informal economic sector [3]. This sector, which employs about $80 \%$ of the Ghanaian work force, has not been fully incorporated into the national development efforts [4]. This fact puts into perspective the inadequacies of poverty reduction programmes which have been limited in their reach as they typically have not worked through this vast sector to develop income-generating activities. The neglect of the informal sector has left microenterprises struggling to meet the many problems (such as lack of capital, poor or no records keeping) that besets the sector, limiting their growth. The challenges for poor rural women are greatest as they tend to be illiterate with little or no access to basic business development services and credit. As a result, most microenterprise owners, especially those in the rural areas, remain poor.

Microenterprise development programmes seek to improve profits by providing business development services including information support services for business improvement, institutional financial services and access to other non-financial services so as to improve profits. Microenterprise development is considered by some to be a promising way to help the working poor, the unemployed, and those who receive public assistance $[5,6]$. On the other hand, other researchers argue that the microenterprise strategy needs better assessment and caution about assertions of its impact [4].

After reviewing studies on capacity for small enterprise development, Quainoo [3] concluded that substantial reduction in rates of malnutrition, especially among infants and young children, could be accomplished through interventions designed to increase women's access to resources that support both their income-earning and caregiving roles-a women's resources approach. Hence, microenterprises owned and operated by women are often the target business entities in poverty reduction and nutrition programmes in Ghana. However, economic gains may not always translate into nutrition benefits and improved child welfare.

The Enhancing Child Nutrition through Animal Source Food Management (ENAM ) project was launched in Ghana in September 2005. The project sought to address income and knowledge barriers to improved child nutrition in Ghana. The project 


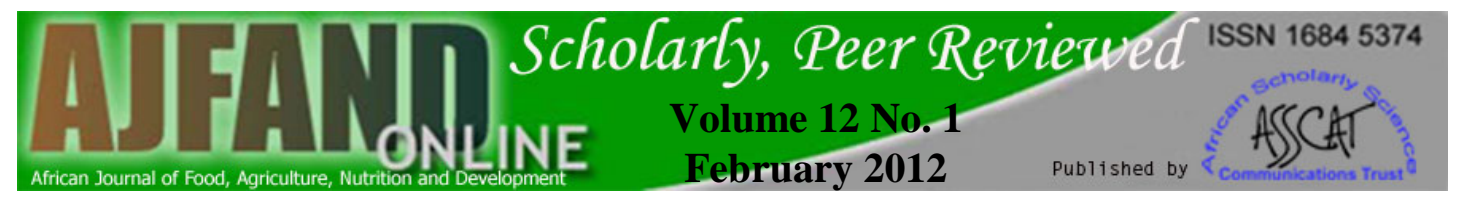

combined microenterprise development (such as microfinance and enterprise development training services) with nutrition education. The present study assessed the effects of caregivers' participation in the microenterprise development activities of the ENAM project on caregivers' enterprise performance and contributions to key household- and child-related expenditures and household consumption of ASF.

\section{MATERIALS AND METHODS}

The primary goal of the ENAM project was to increase the amount of ASF in the diet of 2- to 5-year-olds in rural Ghana. To achieve this goal, three simultaneous services were provided to selected caregivers: (i) entrepreneurship capacity building, (ii) provision of microfinance services (microcredit and savings) and (iii) nutrition education. A diagrammatic representation of the project's conceptual framework is presented in Figure 1. By providing microfinance services as well as entrepreneurship capacity building, the project sought to enhance the economic performance, incomes, and profits from these microenterprises. Credit with Education programmes(Freedom from Hunger) operate with the assumption that an increase in income alone is unlikely to have a substantial impact on nutritional status unless key maternal and child health and nutrition behaviours are adopted. The ENAM project, modelled after the Credit with Education concept provided nutrition education specifically on the nutritional needs of 2- to 5-years-olds as well as how to incorporate ASF in children diet. This present analysis measured the effect of caregivers' income levels on the amount of ASF consumed at the household level. 


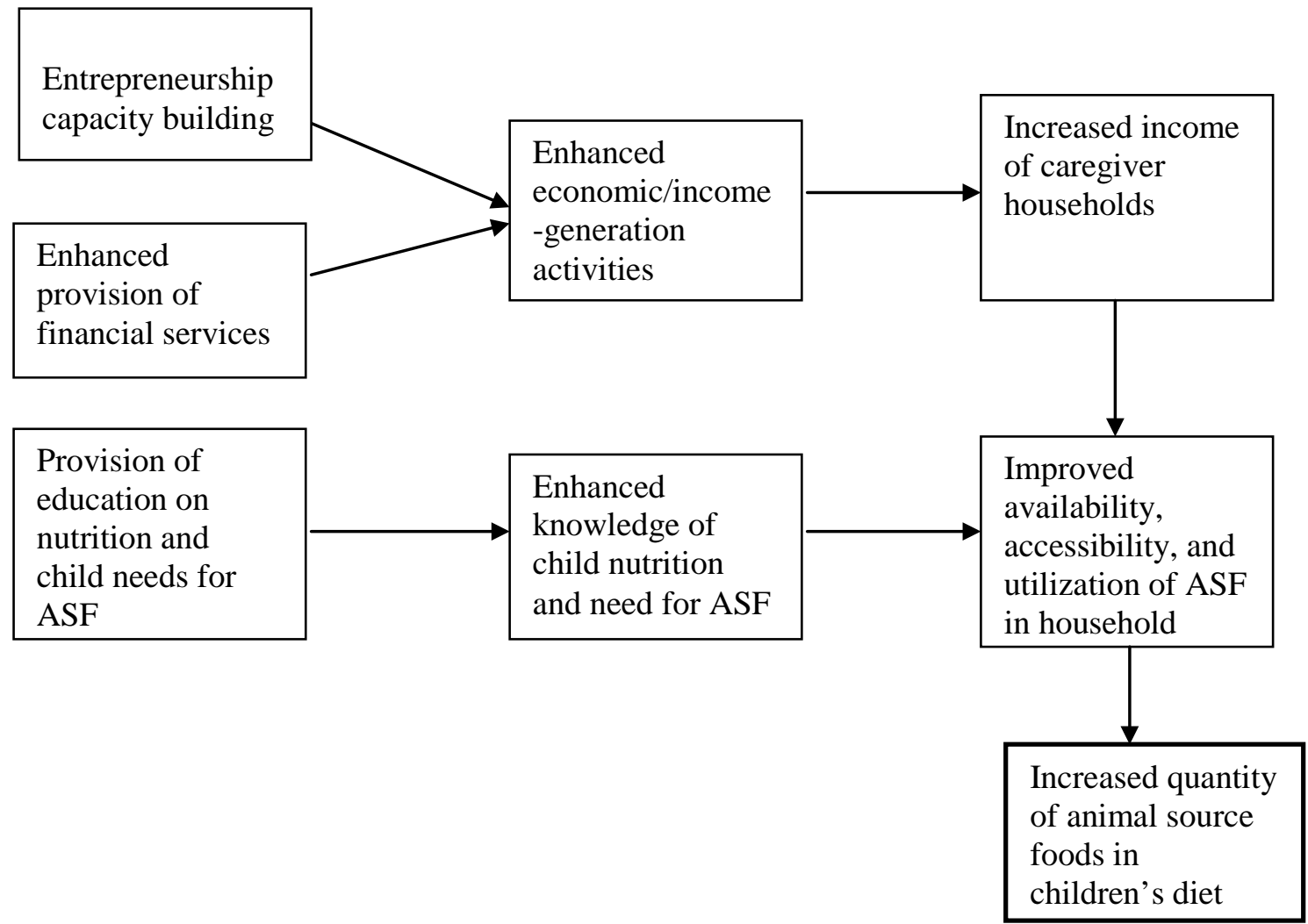

Figure 1: ENAM project's proposed conceptual framework

\section{Study areas and participants}

The ENAM project selected three ecological zones as study sites to represent the variety in availability of ASF in Ghana: Coastal Savannah in the south, ForestTransitional in the middle belt, and Guinea Savannah in the north. Within each selected zone, two communities were selected for the intervention and two communities of similar size and income generating activities were selected as control communities for the purpose of evaluating the impact of the intervention. Study intervention participants were caregivers of 2- to 5-year-olds who self-selected to take part in the education and microcredit activities. Households with 2- to 5-year-old children in the control communities were categorized by their community-based wealth rank and then from each rank, caregivers were randomly selected to make up the non-participant group. The selection resulted in a similar wealth rank distribution in the non-participant households as seen in the participant households. Control communities received none of the intervention activities. 
The present cross-sectional study collected unique socioeconomic information from ENAM households between December 2007 and January 2008. Data collection was carried out in only the Forest Transitional and Coastal Savannah zones by two data collectors supervised by the first author; the Guinea Savannah was not included because of time and resource constraints. These additional data were collected from 80 caregivers who fully participated in the ENAM project (participated in microcredit and micro-savings services, microenterprise services as well as nutrition education) and were available at the time of the field work. Eighty non-participant caregivers who were residents of the control communities in the two zones were also interviewed.

\section{Measurement of variables}

A pre-tested structured questionnaire was used to interview participant and nonparticipant caregivers about their microenterprise profits, enterprise changes in the past two years (2005-2007), financial contributions to household expenditures, and savings. To obtain information on microenterprise profits, the concept of microenterprise profits (defined as total revenue plus the value of enterprise products consumed in the household minus total costs [7]) was explained to the caregivers after which, they were asked to estimate their weekly profit earnings for each of their enterprises. Indicators of enterprise changes assessed were; enterprise expansion (an increase in the volume of goods handled per week), diversification (that is, if the caregiver dealt in a new product), improvement in quality of product (improved packaging, taste in cooked food, or freshness of supply), and sales in new additional market places (markets which were equally accessible to both participant and control groups). Financial contributions to household expenditures was ascertained by asking caregivers about their monetary contributions to food consumed by the household in the past week, as well as contributions to children's medicine, healthcare, school expenses, clothing, and footwear in the past four months. Savings was measured as the amount of cash that a caregiver was able to set aside for the future whether kept in a safe place at home or with a financial institution at the time of data collection.

Most components of the intervention package were targeted at improving profit. However, the nutrition education emphasized the importance and use of ASF and was directed at changing attitudes about ASF consumption by 2- to 5-year-old children. Data were collected on the amount of ASF the household consumed and the amount (in Ghanaian cedis, GHS) that the household had spent on ASF in the previous week. Acquisition information was collected for 11 different categories of ASF: livestock meat, organ meat, bush meat, whole fish, powdered fish, shellfish, snail, poultry, egg, milk and 'others' (such as, 'wele', salted fish). For each of these ASF categories, the caregiver was asked to indicate whether the household consumed it in the previous week, the amount of money spent on it by the household ('amount purchased') as well as the market value of non-purchased but consumed ASF ('non-purchased amount' including gifts, home-bred livestock, payment in-kind for household labour). The amount of each category of ASF consumed in a given household was calculated as the sum of the 'purchased amount' and 'non-purchased amount'. The total amount of ASF consumed in a household was the sum of all 'purchased ASF' plus all 'nonpurchased ASF'. Per capita ASF was the amount of ASF (in monetary value) a

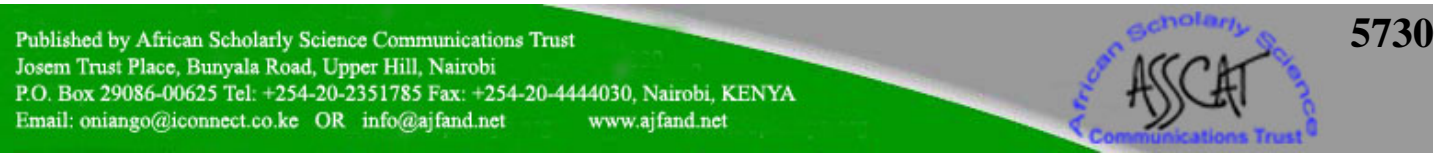


household member consumed per week and it was computed as the ratio of the total amount of ASF consumed in the household to the household size.

\section{Limitation of study}

Due to lack of enterprise records among respondents of the study, the concept of the profit was explained respondents and they were guided to estimate their own profit. Also, caregivers were guided to state and give the market value of ASF consumed by her household including gifts. All these involve the risk of mis-estimating as they rely on memory.

\section{Data analysis}

Data were analyzed using SPSS version 12 . Data were presented as mean \pm standard deviation, standard error mean, or $\mathrm{n}(\%)$ and significance was considered $\mathrm{P}<0.05$ unless otherwise stated. The independent sample Student's t-test or Mann Whitney test for non-normally distributed variables was used to test for differences in participant and non-participant caregivers' mean enterprise profits, savings, and contributions to household-and child-related expenses as well as ASF purchases. Differences in categorical variables such as indicators of enterprise performance and uses of enterprise profits were assessed using the Chi-Square statistic. Double log regression was used to determine the effects of caregivers' enterprise profit and participation in the ENAM project on household's ASF consumption.

\section{Ethics approval}

Ethical approval for the ENAM project was obtained from the Institutional Review Boards of Iowa State University, Noguchi Memorial Institute for Medical Research at the University of Ghana, and McGill University. Written informed consent was obtained from each caregiver prior to data collection.

\section{RESULTS}

The mean number of household members engaged in income generation activities was higher for households of participant caregivers than non-participant caregiver households (Table 1). Dependency ratio tended to be higher for non-participant caregiver households. About $30 \%$ and $49 \%$ of participant and non-participant caregivers respectively, lived in nuclear family arrangements. The prevalence of female-headed households was similar for the two groups of caregivers. There were no significant differences between participant and non participant caregivers with respect to marital status and level of education completed. The most common occupation among the participant caregivers was trading whereas the majority of nonparticipant caregivers were crop farmers.

\section{Enterprise performance}

Participants of the ENAM project performed better in their enterprises than nonparticipants based on their weekly enterprise profits (Table 2). Compared to nonparticipants, a significantly higher proportion of participants reported to have increased their average weekly enterprise profit and this profit tended to be greater 
than that of non-participants $(\mathrm{P}<0.10)$. Savings were higher among participants $(\mathrm{P}<0.05)$ compared to non-participants over a four-month period.

As a reflection of their improved entrepreneurial knowledge and skills, participants were significantly more likely than non-participants to consider their future financial security when making decisions about which income-generating activity to undertaken (37.5\% vs. 3.8\%; $\mathrm{P}<0.01)$.Significantly more participants than nonparticipants used the major part of their enterprise profits for paying their children's school expenses $(\mathrm{P}<0.01)$ as well as making savings deposits $(\mathrm{P}<0.01)$. On the other hand, non-participants were significantly more likely than participants to report spending most of their enterprise profits on buying clothing $(\mathrm{P}<0.05)$ and items for the house $(\mathrm{P}<0.05)$ (Table 3$)$.

\section{Caregivers' monetary contributions}

Participant caregivers made greater monetary contributions towards household food expenses $(\mathrm{P}<0.05)$ and children's school expenses $(\mathrm{P}<0.01)$ than non-participant caregivers (Table 4). Their percentage contributions were significantly greater than that of non-participant caregivers in medicine and healthcare of children $(\mathrm{P}<0.05)$, school expenses $(\mathrm{P}<0.01)$ and children's clothing and footwear $(\mathrm{P}<0.01)$.

\section{Animal Source Foods consumed (in monetary units)}

Over the previous week, participant households spent more on ASF than nonparticipants households $(\mathrm{P}<0.01)$, including a greater amount on livestock meat, shellfish, snail, milk and 'other' ASF (such as 'wele' and salted fish) $(\mathrm{P}<0.05$; Table 5). On average, households of participant caregivers spent GHS4.59 [GH\$1 = US\$ 0.92] more on purchased ASF than non-participant households in the past week $(\mathrm{P}=0.067)$. There was no significant difference in the amounts (in monetary value) of non-purchased ASF between groups. On the whole, the total amount of ASF consumed (purchased plus non-purchased ASF) by households of participant caregivers was greater (GHS 5.61) than the amount consumed by households of nonparticipants in the past week $(\mathrm{P}<0.01)$. The difference in the amount of per capita ASF consumed per week did not reach significance.

\section{Project participation, caregiver enterprise profit and household ASF consumption}

Generally, the total amount of ASF consumed (in GHS) per week by households was about GHS12 for a household whose caregiver had 'low' profit and about GHS16 for households of caregivers who had 'high' profits (profit level was not a significant predictor; Table 6). However, the total mean amount (in GHS) of ASF consumed per week by a household of participant caregiver was almost GHS6 higher than that for household of non-participant caregivers $(\mathrm{P}=0.045)$. Participation in ENAM did not modulate the effect of enterprise profit on ASF consumption (interaction term: $\mathrm{P}=0.492)$.

A double log multiple regression model was run to account for other potential determinants of ASF consumption. Only caregivers' ENAM participation predicted household consumption (in GHS) of ASF; enterprise profits approached significance. 
All other factors including ecological zone, and household (dependency ratio and sex of household head) and caregiver (educational level and marital status) characteristics did not predict household ASF consumption (in GHS) (Table 7).

\section{DISCUSSION}

This study revealed the importance of integrated programs that promote income generating activities and increase enterprise and nutrition knowledge. Those women who participated in the microenterprise development program of the ENAM project had higher weekly enterprise profits through enterprise expansion, diversification, amongst other changes. Credit received by caregivers effectively improved profits as it expanded enterprises and allowed participant caregivers to take advantage of other economic opportunities which their counterparts in control communities could not take access. Ellis and Mdoe [7] previously found that the poorest farmers were most reliant on agriculture and the reliance on agriculture decreased with increased diversification into non-farm income-generating activities.

Higher incomes resulting from credit have been associated with increased capacity utilization, diversification of goods or services sold, or lower cost supplies and raw materials [8]. With respect to lowering costs, a study done in Egypt [9], found a credit programme to reduce reliance on supplier credit, resulting in lower cost of inputs, more choice and greater quality of inputs, and less dependence on supplier controlled marketing channels. Similarly, in Honduras [10] availability of credit prevented some borrowers from having to sell their produce below market rates to landowners and merchants to obtain an advance in the lean season, thus increasing their incomes. Enterprise expansion in this study was mainly an increase in the volume of goods the entrepreneur handled at a time and, in so doing, the unit cost of production and handling charges were reduced and profits were increased. With the increased access to loan, participants were less likely to depend on inputs bought on credit basis (which usually comes at a higher cost), participants were able to produce at reduced cost, and thus improve profits. Other reasons for the improved profit and savings included the fact that more participants experienced enterprise diversification and sales in new market places. Enterprise diversification also improved profit and reduced risk. These changes created by credit gave participants a competitive advantage and could explain their higher profits. In an impact assessment of the Credit with Education programme in Ghana, researchers found out that enterprise expansion and diversification were the main changes in participants' enterprises that led to an increase in their profits [11]. This present study supports these findings.

However, the study noted some disparities in profits earned by caregivers. In an impact study of Credit with Education programme in Lower Pra rural bank in Ghana, similar disparities in enterprise performance were noted and attributed it to differences in individual entrepreneurial abilities [11]. Schreiner and Woller [4] asserted that disparities could be a result of differences in individual traits and the fact that entrepreneurship is difficult to teach. In this study, disparities might also be explained by limited training (at the time data collection, only 39\% of participants had 
received entrepreneurial development training), engagement in a secondary IGA, and the type and size of IGA which determined the size of loan given.

Participant caregivers made significantly greater monetary contribution towards household food and also households of participant caregivers purchased and consumed a greater amount of ASF (in monetary units) than households of nonparticipants. There is evidence from several other studies that microenterprise development programs improve household food security [12]. Tarasuk [13] found out that household food insecurity appeared inextricably linked to financial insecurity. Some of the circumstances that women identified as precipitating acute food shortages in their households included chronically inadequate incomes, the need to meet additional, unusual expenditures, and the need to pay for other services or accumulated debts. A study conducted by Hashemi and Morshed [14] on clients of the Grameen Bank showed that access to credit not only reduced poverty and improved the welfare of participating households, but also increased the energy intakes of household members. In a related study, Bornstein [15] found that the average daily expenditure on food was $21 \%$ higher for client households than for nonclient households. These reports suggest that when people receive additional income (especially the poor) they tend to improve their diets.

Participant caregivers made significantly greater monetary contribution towards childrelated expenses than non-participants. This evidence generally agrees with a previous research by Handa [16], which has shown that higher incomes for women enable them to make greater contributions towards household budget allocated to food and children's goods. In Guatemala, Engle [8] found that for mothers, the percentage of the total family income they earned was most highly associated with children's nutritional status, suggesting that income controlled by mothers may have nutritional benefits for children. This is likely, as it has been shown in this study that participant caregivers who had higher incomes made greater contributions to household food purchases. Also, in a review of studies and experiences in countries where 'Save the Children' microfinance projects operated, it was concluded that microfinance clearly contributed to improvements in children's welfare through increased incomes and thus improved nutrition, housing, health and school attendance, and reduced harmful child labour[10]. Todd's [17] case studies provide interesting insights into how her "women at the centre" managed their diversified sources of income to maximise first food, material and then social security for their families and themselves. The additional income earned by mothers can lead both to empowerment and improvements in family welfare as women are more likely to invest additional income in children and the family [18]. This study supports the notion that when women's' incomes improve, they are more likely to contribute to the welfare of the children in their care..

The higher purchase and consumption of ASF (in monetary units) in households was noted among participant caregivers. Steinfeld et al.'s [19] study pointed out that in order to increase the amount of ASF in people's diet, higher incomes are needed. Bennet's Law also states that households switch from less to more expensive energy consumption, such as from coarse grains to meats and fresh fruits and vegetables, as 
incomes rise [19]. Also in a study by Tarasuk [13], women in households characterized by food insecurity with severe or moderate hunger over the past 30 days reported lower intakes of vegetables, fruits and meat and alternatives than those in households where hunger was not evident. In Lesotho, nutrition education for mothers could contribute to improving children's growth, but only in households that had access to a minimum level of resources [20]. For poorer households, nutrition education alone would not be sufficient. In this study, the higher purchase of ASF was partly as a result of the greater caregiver's income among participants which could be due to microfinance and enterprise development programme.

Freedom from Hunger's Credit with Education strategy assumes that income increases alone are unlikely to have substantial impact on food security and malnutrition unless key health and nutrition behaviours are adopted [11]. This is consistent with the present study results that showed no overall association between profit and ASF consumption. An increased income starts to show its potential detrimental effects on the health of a large population in most developing countries and people in low-income groups are more vulnerable to these effects [21]. This is because extra income may be spent on foods that are not nutritionally beneficial. This study lends support to other findings from South India [22], which showed that the combination of empowerment with knowledge and resources can further reduce malnutrition significantly, more than either of these two inputs alone. Thus improvement in caregivers' income is effective in improving her household's consumption of ASF when the caregiver has received nutrition education. This study has found that households of participant caregivers purchased and consumed more ASF because the greater income was combined with education on the importance and use of ASF for children.

\section{CONCLUSION AND POLICY IMPLICATIONS}

Results of this study reinforce previous evidence that microenterprise development programmes provided to caregivers significantly improve their enterprise performance, which results in higher enterprise profits and savings. Also evidence from this study has confirmed that when caregivers' incomes increase, they are more likely to increase their contributions towards the welfare of their children and other expenditure items that are beneficial to their households. This has a great policy implication in developing countries where poor women are usually engaged in microenterprises. For instance in Ghana where the majority of rural women are illiterate, strengthening existing women enterprises and developing new enterprises for women would effectively increase incomes and reduce poverty.

As shown in this study, developing women's microenterprise does not only improve incomes of participants but also has the potential of improving household's consumption of ASF and children's welfare.

Although this study did not examine changes in caregivers' knowledge, it is possible that the nutrition education received by participants impacted their knowledge, attitudes and practices relative to ASF. This may have accounted for the higher levels 


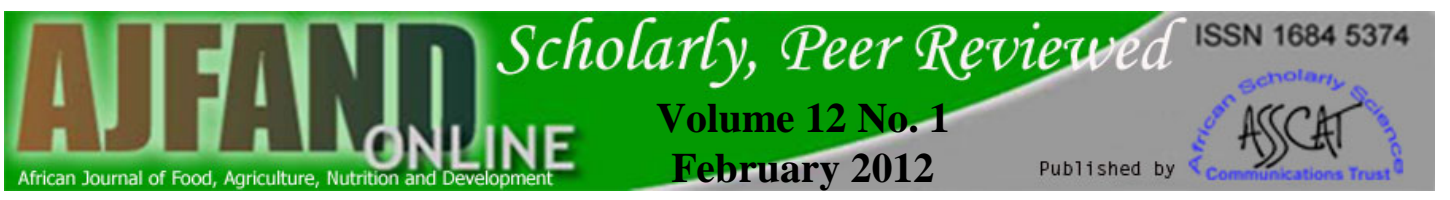

of ASF consumption in households that participated in the ENAM project activities. Thus efforts to improve household nutrition level should combine income improvement programs with nutrition education.

\section{ACKNOWLEDGEMENTS}

This publication was made possible through partial support provided to the Global Livestock Collaborative Research Support Program by the Office of Agriculture, Bureau for Economic Growth, Agriculture and Trade, United States Agency for International Development under terms of Grant No. PCE-G-00-98-00036-00. The opinions expressed herein are those of the author(s) and do not necessarily reflect the views of USAID. 
Table 1: Household and caregivers' characteristics of participants and non-participants of the ENAM intervention in rural Ghana ${ }^{1}$

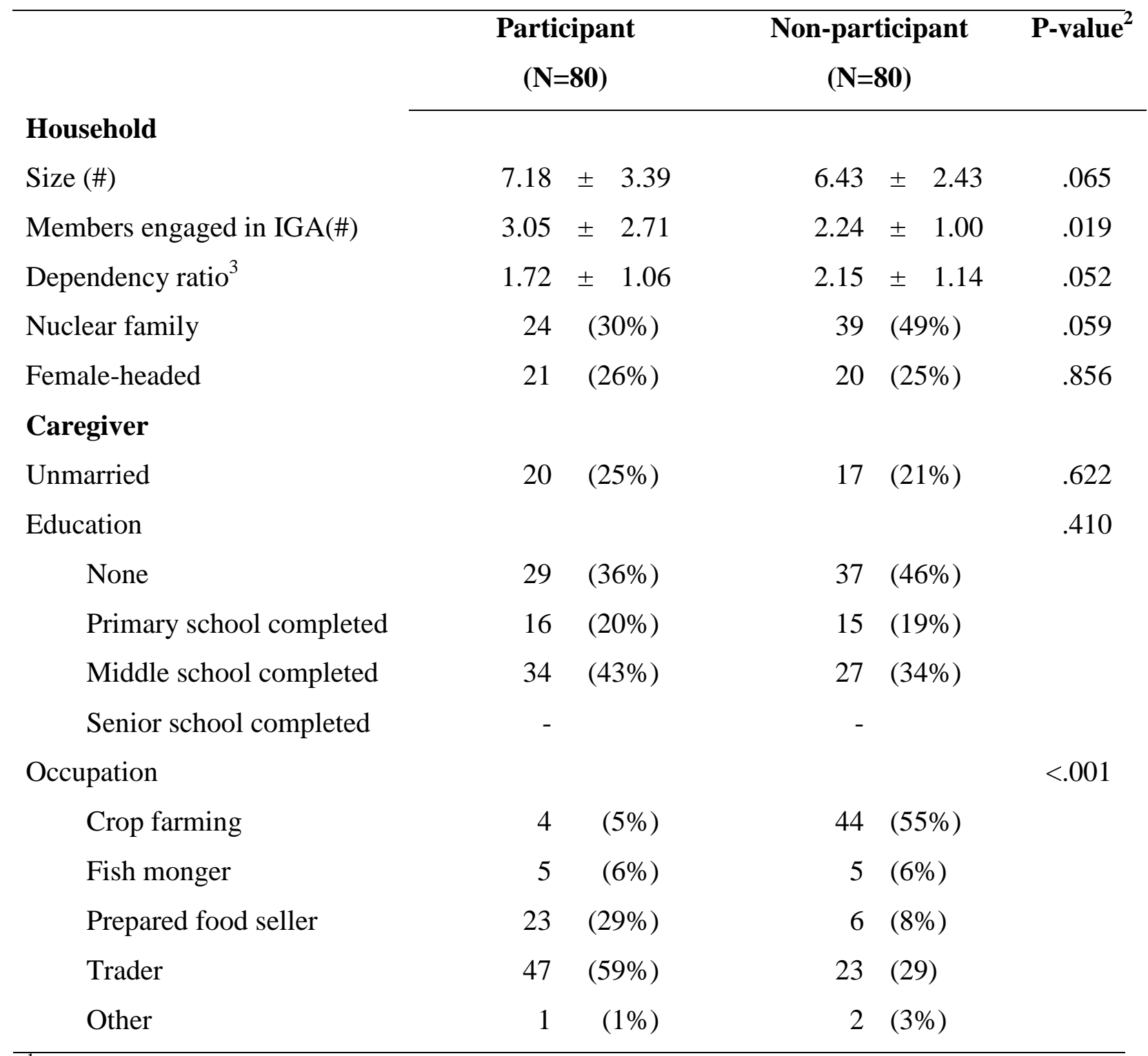

\footnotetext{
${ }^{1}$ Data are shown as mean \pm SD or $\mathrm{n}(\%)$

${ }^{2}$ Significance associated with Pearson Chi-square test for categorical variables, nonparametric chi square test of categorical variables, and Student's t-test for continuous variables

${ }^{3}$ Dependency ratio=number engaged in IGA/household size.
}

IGA: Income Generating Activity 
Table 2: Enterprise performance of participating and non-participating ENAM project caregivers in rural Ghana ${ }^{1}$

\begin{tabular}{|c|c|c|c|}
\hline Characteristics & $\begin{array}{l}\text { Participant } \\
\qquad(\mathrm{N}=\mathbf{8 0})\end{array}$ & $\begin{array}{l}\text { Non-participant } \\
\qquad(\mathbf{N}=\mathbf{8 0})\end{array}$ & P-value $^{2}$ \\
\hline \multicolumn{4}{|l|}{ Changes in enterprise } \\
\hline Expanded enterprise & $66 \quad(82.5)$ & $37 \quad(46.3)$ & .004 \\
\hline Enterprise diversified & 19 (23.8) & $5 \quad(6.3)$ & .004 \\
\hline \multicolumn{4}{|l|}{ Other positive changes } \\
\hline experienced $^{3}$ & $43 \quad(53.8)$ & $9 \quad(11.3)$ & $<.001$ \\
\hline \multicolumn{4}{|l|}{ Profit $^{4}$} \\
\hline Reported change & & & $<.001$ \\
\hline Increased & $65 \quad(81.2)$ & $25 \quad(31.3)$ & \\
\hline Decreased/stayed same & 15 (18.8) & $55 \quad(68.7)$ & \\
\hline Amount of profit $(\mathrm{GH} \phi)$ & $19.30 \pm 2.21$ & $12.21 \pm 1.86$ & .080 \\
\hline \multicolumn{4}{|l|}{ Savings ${ }^{4}$} \\
\hline Reported change & & & $<.001$ \\
\hline Increased & $56 \quad(70.0)$ & 10 (12.5) & \\
\hline Decreased/stayed same & $22 \quad(27.5)$ & $30 \quad(37.5)$ & \\
\hline No savings & $2 \quad(2.5)$ & $40 \quad(50.0)$ & \\
\hline Amount saved (GHф) & $62.88 \pm 1.68$ & $26.25 \pm 3.63$ & .036 \\
\hline \multicolumn{4}{|c|}{${ }^{1}$ Data shown as $\mathrm{N}(\%)$ or mean \pm SEM for amount saved and weekly profit of IGA } \\
\hline \multicolumn{4}{|c|}{$\begin{array}{l}{ }^{2} \text { Pearson's Chi-square test for categorical variables and Student's t-test for continuous } \\
\text { variable }\end{array}$} \\
\hline \multicolumn{4}{|c|}{${ }^{3}$ Other changes included location of new market and an improvement in the product } \\
\hline $\begin{array}{l}{ }^{4} \text { Caregivers' weekly profit an } \\
(96.3 \%) \text { participants and } 35(4\end{array}$ & $\begin{array}{l}\text { ings from their } \\
\text { b) non-participar }\end{array}$ & $\begin{array}{l}\text { US\$ } 1=\text { Ghana Cec } \\
\text { isclosed their savin }\end{array}$ & $0.92 ; 77$ \\
\hline
\end{tabular}


Table 3: Major uses of enterprise profits by participating and non-participating Ghanaian caregivers in the ENAM project ${ }^{1}$

\begin{tabular}{lcccc}
\hline Uses of enterprise profits & Total & Participant & Non-participant & P-value $^{2}$ \\
& $\mathbf{( N = 1 6 0 )}$ & $\mathbf{( N = 8 0 )}$ & $\mathbf{( N = 8 0 )}$ & .324 \\
\hline Buy food & $102(63.8 \%)$ & $54(67.5 \%)$ & $48(60.0 \%)$ & .040 \\
Buy clothing & $81(50.6 \%)$ & $34(42.5 \%)$ & $47(58.8 \%)$ & .006 \\
Pay school expenses & $97(60.6 \%)$ & $57(71.3 \%)$ & $40(50.0 \%)$ & 1.00 \\
Pay health related costs & $28(17.5 \%)$ & $14(17.5 \%)$ & $14(17.5 \%)$ & .008 \\
Buy items for the house & $36(22.5 \%)$ & $11(13.8 \%)$ & $25(31.3 \%)$ & .189 \\
Reinvests in enterprise & $37(23.1 \%)$ & $15(18.8 \%)$ & $22(27.5 \%)$ & .000 \\
Save & $66(41.3 \%)$ & $46(57.5 \%)$ & $20(25.0 \%)$ & .633 \\
Other & $20(12.5 \%)$ & $9(11.3 \%)$ & $11(13.8 \%)$ & .155 \\
Unknown & $2(1.3 \%)$ & $0(0 \%)$ & $2(2.5 \%)$ & \\
\hline${ }^{1}$ Data shown as N (\%) & & &
\end{tabular}


Table 4: Contributions to household and child-related expenses of participating and non-participating caregivers in the ENAM project in rural Ghana ${ }^{1}$

\begin{tabular}{|c|c|c|c|}
\hline Characteristics & $\begin{array}{l}\text { Participant } \\
\qquad(\mathrm{N}=\mathbf{8 0})\end{array}$ & $\begin{array}{l}\text { Non-participant } \\
\qquad(\mathbf{N}=\mathbf{8 0})\end{array}$ & P-value ${ }^{2}$ \\
\hline
\end{tabular}

Mean amount contributed

by caregivers $(\mathbf{G H} \phi)^{3}$

Household food

$6.0 \pm 8.3$

$4.0 \quad \pm 5.3$

.043

Healthcare of children

$2.1 \pm 4.8$

$1.7 \quad \pm 3.8$

.809

School expenses

$20.9 \pm 4.2$

$12.5 \pm 1.4$

$<.001$

Child clothing and footwear

$13.3 \pm 3.2$

$12.4 \pm 4.8$

.482

$\%$ contribution from caregivers

Household food

$50.8 \pm 3.5$

$41.8 \pm 4.1$

.061

Healthcare of children

$40.0 \quad \pm 5.0$

$7.2 \pm 4.7$

School expenses

$62.6 \pm 4.2$

$31.6 \pm 4.4$

$<.001$

Child clothing and footwear

$19.0 \pm 4.4$

$36.7 \pm 4.6$

$<.000$

${ }^{1}$ Data shown as mean \pm SD for mean amount contributed by caregivers and mean \pm SEM for $\%$ contribution from caregivers

${ }^{2}$ Significance associated with Student's t-test (Mean amount contributed) and Mann Whitney Test for non-normally distributed variables (\% contribution from caregivers)

${ }^{3} \mathrm{US} \$ 1=$ GHS $\$ 0.92$ 
Table 5: Amount of money (Ghana cedis) spent within the past week on Animal Source Foods (ASF) consumed by households of caregivers participating and not participating in the ENAM project in rural Ghana ${ }^{1,2}$

\begin{tabular}{|c|c|c|c|c|c|}
\hline \multirow{2}{*}{\begin{tabular}{|l} 
ASF category \\
Livestock meat
\end{tabular}} & \multicolumn{2}{|c|}{ Participant } & \multicolumn{2}{|c|}{ Non-participant } & \multirow{2}{*}{$\begin{array}{c}\text { P-value }^{3} \\
.015\end{array}$} \\
\hline & 2.88 & \pm 0.62 & 1.68 & \pm 2.86 & \\
\hline Organ meat & 0.72 & \pm 1.98 & 0.47 & \pm 1.25 & .389 \\
\hline Bush meat & 1.10 & \pm 1.99 & 0.47 & \pm 1.99 & .179 \\
\hline Whole fish & 3.71 & \pm 0.07 & 3.35 & \pm 0.40 & .235 \\
\hline Powdered fish & 0.98 & \pm 0.65 & 0.44 & \pm 0.08 & .229 \\
\hline Shellfish & 0.38 & \pm 0.05 & 1.60 & \pm 0.09 & .004 \\
\hline Snails & 0.25 & \pm 1.14 & 0.10 & \pm 0.03 & .008 \\
\hline Poultry & 3.02 & \pm 0.51 & 2.15 & \pm 0.26 & .153 \\
\hline Egg & 0.79 & \pm 0.24 & 0.40 & \pm 0.07 & .186 \\
\hline Milk & 0.66 & \pm 0.24 & 0.40 & \pm 0.07 & .008 \\
\hline Other ASF & 0.15 & \pm 0.07 & 0.03 & \pm 0.01 & .001 \\
\hline \multicolumn{6}{|l|}{ Total ASF } \\
\hline Purchased & 11.03 & \pm 3.50 & 6.44 & \pm 0.78 & .067 \\
\hline Non-purchased ${ }^{4}$ & 5.87 & \pm 0.73 & 4.90 & \pm 0.66 & .648 \\
\hline $\begin{array}{l}\text { Total ASF consun } \\
\text { household/week }^{5}\end{array}$ & 16.09 & \pm 1.59 & 10.49 & \pm 0.72 & .001 \\
\hline \multicolumn{6}{|l|}{ Per capita ASF } \\
\hline consumption $^{6}$ & 2.75 & \pm 0.33 & 2.08 & \pm 0.27 & .162 \\
\hline
\end{tabular}

${ }^{1}$ Data are presented as mean \pm SEM

${ }^{2}$ US\$1 = GHS 0.92

${ }^{3}$ Significance associated with Mann-Whitney test for non-normally distributed variables

${ }^{4}$ Amount of non-purchased ASF was given the current market value of ASF

${ }^{5}$ Household ASF consumption $=$ total purchased + non-purchased ASF

${ }^{6}$ Per capita ASF consumption = household consumption $/$ \# household members 
Table 6: Total amount (Ghana cedis) of ASF consumed by household, by caregiver's participation in ENAM project and enterprise profit ${ }^{1,2}$

\begin{tabular}{|c|c|c|c|c|}
\hline Respondent & Rank of profit $^{3}$ & No. & & \\
\hline \multirow{6}{*}{ Participants } & Low & 28 & $14.57 \pm$ & 9.85 \\
\hline & Medium & 28 & $15.45 \pm$ & 12.60 \\
\hline & High & 24 & $18.63 \pm$ & 19.59 \\
\hline & Total & 80 & $16.10 \pm$ & 14.21 \\
\hline & Low & 43 & $10.22 \pm$ & 6.74 \\
\hline & Medium & 28 & $11.45 \pm$ & 6.78 \\
\hline \multirow{2}{*}{ Non-participants } & High & 9 & $8.75 \pm$ & 3.60 \\
\hline & Total & 80 & $10.49 \pm$ & 6.47 \\
\hline \multirow[t]{4}{*}{ Total } & Low & 71 & $11.94 \pm$ & 8.32 \\
\hline & Medium & 56 & $13.45 \pm$ & 10.23 \\
\hline & High & 33 & $15.94 \pm$ & 17.29 \\
\hline & Total & 160 & $13.29 \pm$ & 11.36 \\
\hline
\end{tabular}

${ }^{1}$ Data are presented as mean $\pm \mathrm{SD}$

${ }^{2}$ US\$1 $=$ GHS 0.92

${ }^{3}$ Rank of enterprise profit: Low: $<$ GSH10; Medium: GHS 10-20; High: $>20$

${ }^{4}$ Significance tested with ANOVA:

\begin{tabular}{lccc} 
Source & $\begin{array}{c}\text { Mean Sq } \\
(\mathbf{1 0 0 , 0 0 0 )}\end{array}$ & F & P-value \\
\hline Intercept & 220.801 & 650.766 & .000 \\
& & & \\
Participation in ENAM & 11.725 & 12.840 & .045 \\
& & & \\
Enterprise profits & .243 & .277 & .783 \\
Participation* Enterprise profit & .879 & .713 & .492
\end{tabular}


Table 7: Double log multiple regression model of factors associated with ASF purchased for household consumption in household per week (in Ghana cedis)

\begin{tabular}{lccc}
\hline Variable & Coefficient & t-Statistic & P-value \\
\hline Constant & 13.08195 & 5.680588 & 0.000 \\
Caregiver's enterprise profit (థ) & -0.361258 & -1.873415 & 0.063 \\
Ecological zone (Forest Transitional zone ) & 0.490066 & 1.157978 & 0.249 \\
Dependency ratio & -0.277251 & -0.733746 & 0.464 \\
Household head (female ) & 0.052808 & 0.114622 & 0.909 \\
JSS/middle school completed & 0.082579 & 0.147356 & 0.883 \\
No formal education & 0.145047 & 0.260748 & 0.795 \\
Married & -0.010100 & -0.021001 & 0.983 \\
Household size (\#) & 0.380262 & 0.760114 & 0.448 \\
Participant in ENAM nutrition education & 0.921021 & 2.235581 & 0.027
\end{tabular}

R-squared: 0.064477

F-statistic: 1.133358 


\section{REFERENCES}

1. Allen LH Intervention for micronutrient deficiency control in developing countries: Past, present and future. J. Nutr. 2003; 133(11): 3875S - 3878.

2. Colecraft EK, Marguis GS, Aryeetey R, Sakyi-Dawson O, Lartey A, Ahunu $B$ and $\mathbf{E}$ Canacoo Constraints on the use of animal source foods for young children in Ghana: A participatory rapid appraisal approach. Ecol. Food Nutr. 2006; 45: 351-377.

3. Quainoo AA Building the Capacity for Small Enterprises Development in Experiences in Capacity-Building for Ghanaian Women. Asempa Publishers, Ghana. 2001.

4. Schrenier $\mathbf{M}$ and $\mathbf{G}$ Woller Microenterprise development programs in the United States and the developing world. World Devel.2003; 31(9): 1567-1580.

5. Clinton HF, In: CA Severence \& AK Kays (Eds). Directory of US Microenterprise Programme Washington, D.C Aspen Institute 1997.

6. Raheim $\mathbf{S}$ and $\mathbf{C F}$ Alter Self-employment as a Social and Economic Development Intervention for Recipients of AFDC. J. Comm. Pract. 1998; 5(1-2):41-61.

7. Ellis $\mathbf{F}$ and $\mathbf{N}$ Mdoe Livelihoods and rural poverty reduction in Tanzania. World Devel. 2003;31(8):1367-1384.

8. Lisa D "Measuring Profits and Net worth of Microenterprise: a Field Test of Eight Proxies assessing the impact of Microenterprise Services management systems international 600 water street S.W". Washington, DC: 1999. http://pdf.usaid.gov/pdf_docs/PNACK429.pdf (Accessed August 26, 2010)

9. Mordurch $\mathbf{J}$ and $\mathbf{B}$ Haley "Analysis of the Effects of Microfinance on Poverty Reduction”. NYU Wagner Working Paper No. 1014. 2002. http://www.nyu.edu/wagner/workingpapers.html Accessed August 26, 2010)

10. Marcus R, Porter B and C Harper Money Matters: Understanding Microfinance (Save the Children Working Papers). London: Save the Children. 1999.

11. McNelly B and C Dunford "Impact of Credit with Education on Mothers and Their Young Children's Nutrition: Lower Pra Rural Bank Credit with Education Program in Ghana.” Freedom from Hunger Research Paper No. 4. Davis, CA: Freedom from Hunger. 1998. 
12. Kennedy E and P Peters Household Food Security and Child Nutrition: The Interaction of Income and Gender of Household Head. World Devel. 1992; 20(8): 1077-1085.

13. Tarasuk VS Household Food Insecurity with Hunger Is Associated with Women's Food Intakes, Health and Household Circumstances. J. Nutr. 2001; 131: $2670-2676$.

14. Hashemi SM and L Morshed "Grameen Bank: A Case Study.” In: Wood G.D. and I. Sharif, eds. "Who Needs Credit? Poverty and Finance in Bangladesh” University Press Limited, Dhaka, 1997.

15. Bornstein D The Price of a Dream. Simon \& Schuster, New York, 1996.

16. Handa S Maternal Education and Child Height. Econ Devel Cult Change 1999;47(2):421-439.

17. Todd H Woman at the Centre: Grameen Bank after One Decade. Dhaka: University Press Limited. 1996.

18. Engle PL Influences of mothers and father's income on children's nutritional status in Guatemala. Soc. Soc. Med. 1993; 37(11):1303-1312.

19. Steinfeld H, $\mathbf{T}$ Wassenaar and $\mathbf{S}$ Jutzi "Livestock production systems in developing countries: status, drivers, and trends”. Rome: Animal Production and Health Division, Food and Agriculture Organization. 2006.

20. Ruel MT, Habicht JP, Pinstrup-Andersen P and Y Gröhn The Mediating Effect of Maternal Nutrition Knowledge on the Association between Maternal Schooling and Child Nutritional Status in Lesotho. Am J Epidemiol. 1992; 135(8): 904-914.

21. Shufa D, Mroza TA, Zhaib F and BM Popkin Rapid income growth adversely affects diet quality in China particularly for the poor. Soc. Sci. Med. 2004; 59: 1505-1515.

22. Sethuraman K, Lansdown $\mathbf{R}$ and $\mathbf{K}$ Sullivan Women's empowerment and domestic violence: The role of sociocultural determinants in maternal and child undernutrition in tribal and rural communities in South India. Food Nutr. Bull. 2006; 27: 128-143. 